\title{
Effects of carrageenan as elicitor to stimulate defense responses of basil against Cuscuta campestris Yunck
}

\author{
Effat Ahmadi Mousavi ${ }^{\star 1}$, Khosrow Manochehri Kalantari ${ }^{1}$, Fatemeh Nasibi ${ }^{1}$, Hakimeh Oloumi ${ }^{2}$ \\ ${ }^{1}$ Biology Department, Faculty of Science, Shahid Bahonar University of Kerman, Kerman, Iran \\ ${ }^{2}$ Ecology Department, Institute of Science and High Technology and Environmental Sciences, Graduate University of \\ Advanced Technology, Kerman, Iran
}

\begin{abstract}
Cuscuta campestris is a holostemparasitic plant that obtains its resources from its hosts. Sweet basil is an important commercial plant, widely cultivated in many countries. It is a common host for C. campestris. Generally, $C$. campestris has negative effect on the growth of infected plants and its infestation is difficult to control. Therefore, environmental friendly control of C. campestris seems to be useful. In this work, the relationship between C. campestris and its host, sweet basil, and effects of $\kappa$-carrageenan on protection against $C$. campestris and suppression of its invasion were studied. Basil was sprayed with a solution of carrageenan at a final concentration of $1 \mathrm{~g} \mathrm{~L}^{-1}$, once a week, 3 times in total. Infection of basil with C. campestris was performed 2 days after the last carrageenan treatment and the plants were collected two weeks after $C$. campestris attachment. In this study, phenylalanine ammonia-lyase activity (PAL), phenolic, flavonoids and antioxidant content increased remarkably in the basil plants parasitized with $C$. campestris, and therefore it seems that the parasitic plant induced a defense response in the host plants. Treatment with carrageenan significantly increased shoot length and leaf area of basil and decreased C. campestris infestation by about 26\%. Carrageenan treatment caused a significant increase in PAL activity, phenols, antioxidant and lignin content in basil. Thus, the present observation suggested the phenylpropanoid pathway was activated and defense responses were stimulated. Our results showed that carrageenan spraying induced beneficial effects in plants, corresponding to growth stimulation and defense compound synthesis. Thus carrageenan treatment is recommended as a natural biostimulator for the protection of plants against C. campestris.
\end{abstract}

Keywords: carrageenan, defense against parasites, field dodder, Ocimum basilicum

\section{Introduction}

Among plants with medicinal value, plants of the genus Ocimum (Lamiaceae) are very important for their therapeutic potentials (Ramasubramania 2012). Sweet basil (Ocimum basilicum L.) is an important species of the genus Ocimum that grows in different parts of the world (Tewari et al. 2012). Sweet basil is an annual plant native to Asia that is cultivated as a field crop in the Mediterranean countries and is widely used in food (for flavour) and in oral care. The essential oil of the plant is additionally used in perfumery (Tewari et al. 2012). Leaves and flowers of basil are traditionally used as digestive, antispasmodic, stomachic, carminative, galactagogue, aromatic and tonic agents (Gülçin et al. 2007). Antimicrobial and antiviral activities of this plant have also been reported (Chiang et al. 2005).

Sweet basil is a common host for the stem-parasitic plant Cuscuta campestris Yunck. with the common name of field dodder. This parasite is one of the major constraints that limit the productivity of basil (Behbahani 2014) and therefore the parasitic interaction of $C$. campestris with its hosts seems interesting. C. campestris is a well known member of the Cuscuta genus, of which it is the most widespread species. It is a holostemparasitic plant without leaves and roots, but it can produce absorptive haustoria that provide physical and physiological bridges between the parasite and its host (Kushan et al. 2006). It can infect various host species (Dawson et al. 1994), self-parasitize and hyper-parasitize (Liao et al. 2005). Upon successful creation of vascular connections with the host, Cuscuta becomes a strong sink, withdrawing water, ions, sugars, amino acids and other nutrients. It obtains its resources entirely from its host plants (Dawson et al. 1994). Cuscuta-infested plants gradually become weak, resulting in decline in growth and yield (Aly 2013). In addition to its impact on ornamentals, native plants and forage crops, it has been reported that Cuscuta can suppress or kill

* Corresponding author, e-mail: effatmousavi@yahoo.com 
vegetables and weeds (Fathoulla and Duhoky 2008). Control of Cuscuta spp. is extremely difficult, thus it causes huge losses in agriculture (Shen et al. 2007).

Natural extracts from plants and other organism for protecting crops from pathogens and pests have recently been reported. They protect plants without negatively affecting the growth and yield (Kapooria et al. 2007, Aly 2013).An effective method of achieving crop protection is inducing resistance by activating natural protection system with elicitors that are environmentally safe. It has been reported that this strategy is effective and was used against a vast range of pathogens, pests and parasites, including fungi, bacteria, viruses, insects and herbivores (Halim et al. 2004), but there is no report of such method being used for the control of parasitic plants, especially C. campestris. The major elicitors described in literature are varied in nature and include oligosaccharides, polysaccharides, glycopeptides, lipids, peptides and proteins and are derived from cell wall, culture filtrate and cytoplasm of different parasitic and nonparasitic plant pathogens (Rao et al. 1996, Halim et al. 2004). In most cases natural elicitor activity is related with the polysaccharide fraction of the varied preparations. Other elicitors derived from plants can be linear or ramified oligosaccharides and polysaccharides (Creelman and Mullet 1997). It is well documented that polysaccharides purified from algae as well as derived oligosaccharides have the capacity to trigger plant defense responses (Potin et al. 1999, Khan et al. 2009).

Liquid extracts obtained from seaweeds have been reported to stimulate the growth of plants, improve resistance to diseases and pests, amend resistance to abiotic stresses (e.g., temperature extremes, salinity, drought and heavy metal stress), increase yield and quality, enhance mineral uptake from soil and antioxidant properties (Zhang et al. 2003, Bi et al. 2008, Khan et al. 2009, Craigie 2011, Naeem et al. 2012, Hashmi et al. 2012). The best-characterized seaweed elicitors that have been reported are laminarin (from the brown seaweeds Laminaria digitata) and carrageenans (from species of red seaweeds of the class Rhodophyceae) that have the potential to activate disease resistance in plants and animals (Gonzàlez et al. 2013b). Carrageenans are the major polysaccharides existing in many red macroalgae (Jatinder et al. 2011). These gel-forming polysaccharides have a linear structure of $\mathrm{D}$-galactose residues joined with alternating $\alpha-(1,3)$ and $\beta-(1,4)$ linkages which are substituted for by one (kappa ( $\kappa$ )-carrageenan), two (iota (l)-carrageenan), or three (lambda $(\lambda)$-carrageenan) ester-sulphonic groups per di-galactose repeating unit (Mercier et al. 2001, Gonzàlez et al. 2013a). Mercier et al. (2001) reported that k-carrageenan elicited numerous plant defense responses, probably through the effect of its high sulphate content, and induced signaling and defense gene expression in tobacco leaves. Since carrageenans have been shown to activate plant defense responses against pathogens (Bi et al. 2011, Shukla et al. 2016), it is plausible that carrageenans might stimulate resistance in plants to parasitic plants like Cuscuta. However, the effect of carrageenans on plant resistance in the face of C. campestris is not known. Most elicitors derived from plants or al- gae stimulate plant defense responses, mainly through the activation of the phenylpropanoid pathway (La Caméra et al. 2004). The stimulation of the phenylpropanoid pathway produces phenolic compounds such as phytoalexins, lignins and salicylic acid, with potential defensive activities (Lattanzio et al. 2006). Thus, the purpose of this study was to investigate how carrageenan acts as elicitor to stimulate growth and defense responses to $C$. campestris infestation in sweet basil plants.

\section{Materials and methods}

\section{Plant material and treatments}

Sweet basil (Ocimum basilicum L.) seeds were sterilized by immersing them in $0.1 \%(\mathrm{w} / \mathrm{v})$ sodium hypochlorite solution for $5 \mathrm{~min}$ and then washed extensively with distilled water and finally rinsed with sterile water. Pots $(14 \mathrm{~cm}$ diameter $\times 12 \mathrm{~cm}$ height) were filled with a homogenous mixture of soil and organic manure (4:1). Physicochemical characteristics of the soil were: texture - sandy loam, $\mathrm{pH}$ (1:2) (soil:water, v:v) 7.2 and electrical conductivity (1:2) (soil:water, v:v) $0.43 \mathrm{dS} \mathrm{m}^{-1}$ (Hanlon 2015). Basil and Cuscuta campestris grow best under conditions of high light, moisture and temperature, these conditions are provided in a natural environment, and therefore the pot experiment was conducted in natural conditions on June, 2015. All experiments were repeated twice. The repetition of cultivation and experiments was conducted in the following year (2016). Basil seeds were planted at $2 \mathrm{~cm}$ depth in the center of each pot. Most seedlings emerged above the soil surface 4 days after planting and were kept then thinned to 8 plants per pot and the pots were watered when required.

Pure $\kappa$-carrageenan (Sigma-Aldrich, USA) was dissolved in hot deionized water. A concentration of carrageenan solution $\left(1 \mathrm{~g} \mathrm{~L}^{-1}\right)$ was finally prepared for foliar spray treatments. The first carrageenan treatments were applied to the basil plants 14 days after sowing, when the plants were at the 2 true leaf stages. Carrageenan solution was sprayed on the upper and lower surface of basil leaves and on the stem, while the 2nd and 3rd sprays were done one and two weeks after the first treatment, respectively. Control plants were sprayed with deionized water.

C. campestris is simply transferable to host plants by vegetative propagation. Significant changes in the amount of metabolites at the apical region of filament indicate that this region is most active during haustorium development for parasitization (Furuhashi et al. 2012). Placement of actively growing Cuscuta spp. stems on host plants usually results in the formation of haustoria and thus causes a new C. campestris plant (Hong et al. 2011). Therefore, threadlike stems (120 mm from tip) of C. campestris without haustorium were separated and placed on the top of 30-day-old basil stem. The basil plants were treated two days in advance with carrageenan before $C$. campestris inoculation. The $C$. campestris was allowed to attach to plants. Usually, C. campestris stem attaches to basil shoot one day after inoculation. The threadlike stem of C. campestris and parasitized basil leaves 
(third row of opposite leaves counted from the cotyledon node) were collected 2 weeks after C. campestris attachment, the carrageenan treated and un-treated healthy basil leaves (third row of opposite leaves counted from cotyledon) were harvested 44 days after sowing. Performance of the plant was assessed in terms of growth attributes (infestation percentage, the plant height and leaf area), and biochemical parameters (with three biological replications).

\section{Infestation percentage of $C$. campestris}

For analysis of defense against $C$. campestris invasion and measuring of infestation of basil plants by C. campestris, the percentage of $C$. campestris tight coupling (its haustorium penetration) to basil shoot was determined 14 days after the infection. The experiments comprised twenty replications and were repeated twice.

\section{Plant growth parameters}

The height of a plant is the vertical distance from the soil at its base to the highest point reached with all parts in their natural position. The height of the basil plant in its natural position was measured. The experiments comprised twenty replications and were repeated. The methods for leaf area measurement include weighing, copying the shape of the 5 th leaf counted from cotyledon on a fragment of paper and weighing the copy. So leaf area is estimated by the following equation: $\mathrm{LA}=\mathrm{W} / \mathrm{c}$, where $\mathrm{LA}$ is the leaf area, $\mathrm{W}$ is the weight of the paper and $c$ is the coefficient of the paper (weight of unit area). The experiments comprised twenty replications and were repeated twice.

\section{Phenolic content analysis}

In order to measure total phenolic content, fifty milligrams of plant material of each sample (the 5 th basil leaf counted from the cotyledon node and threadlike stem of $C$. campestris) were ground and dissolved in $1 \mathrm{~mL}$ of $80 \%$ ethanol, using pestle and mortar. The homogenate was kept at $25^{\circ} \mathrm{C}$ for $24 \mathrm{~h}$ in the dark. Then it was brought to a volume of $5 \mathrm{~mL}$ with ethanol and centrifuged at $2000 \mathrm{~g}$ for $10 \mathrm{~min}$. Soluble phenolic content was analyzed by the method of Gao et al. (2000), using the Folin-Ciocalteu reagent. One hundred $\mu \mathrm{L}$ of extract was mixed with Folin-Ciocalteu reagent (200 $\mu \mathrm{L})$ and distilled water $(2 \mathrm{~mL})$ and incubated at room temperature for $3 \mathrm{~min}$. After incubation, a sample of aqueous sodium carbonate $(20 \% \mathrm{w} / \mathrm{w}, 1 \mathrm{~mL})$ was added to the mixture. The phenolics were measured after one hour of incubation at room temperature. The absorbance of the resulting blue color was determined at $765 \mathrm{~nm}$. Gallic acid was used as a standard and the results were expressed in milligrams of gallic acid equivalent per gram fresh weight of leaf. The experiments comprised three replications and were repeated twice.

In order to measure total flavonoids, nine hundred milligrams of plant material of each sample (the 5 th basil leaf counted from the cotyledon node and the threadlike stem of C. campestris) were ground and dissolved in $3 \mathrm{~mL}$ of $80 \%$ methanol, using mortar and pestle. The homogenate was kept at $25^{\circ} \mathrm{C}$ in the dark. Then it was brought to a volume of $3 \mathrm{~mL}$ with methanol and centrifuged at $2000 \mathrm{~g}$ for $10 \mathrm{~min}$. Total flavonoid content was determined according to the aluminium chloride colorimetric method (Chang et al. 2002). Two $\mathrm{mL}$ of extracts $\left(0.3 \mathrm{~g} \mathrm{~mL}^{-1}\right)$ in methanol were mixed with $0.1 \mathrm{~mL}$ of $10 \%$ aluminium chloride hexahydrate, 0.1 $\mathrm{mL}$ of potassium acetate $(1 \mathrm{M})$ and $2.8 \mathrm{~mL}$ of distilled water. After $40 \mathrm{~min}$ incubation at room temperature, the absorbance of the reaction solution was determined spectrophotometrically at $415 \mathrm{~nm}$. Quercetin was chosen as a standard (standard concentration range: 12 to $200 \mathrm{mg} \mathrm{L}^{-1}$ ) and the results were expressed in milligrams of quercetin equivalent per gram fresh weight of leaf.

Anthocyanin content was determined according to a modified Wagner (1979) method. The plant material of each sample ( $0.1 \mathrm{~g}$ of the 5 th basil leaf counted from the cotyledon node and the threadlike stem of $C$. campestris) was crushed in $10 \mathrm{~mL}$ acidified methanol [methanol: $\mathrm{HCl}(99: 1, \mathrm{v}: \mathrm{v})]$. The tissues were soaked and incubated at room temperature for $24 \mathrm{~h}$ in the dark. The extracts were then centrifuged at 4000 $\mathrm{g}$ for $10 \mathrm{~min}$ at $25^{\circ} \mathrm{C}$. The absorption of the supernatant was read spectrophotometrically at $550 \mathrm{~nm}$. To calculate the amount of anthocyanins, the extinction coefficient $33000 \mathrm{~L}$ $\mathrm{mol}^{-1} \mathrm{~cm}^{-1}$ was used and it was expressed as $\mu \mathrm{mol}$ per gram fresh weight of leaf.

\section{Antioxidant activity}

The antioxidant activity of plant material of each sample was assessed by a modified Girennavar method (2007), using the stable free radical 2, 2-diphenyl-1-picrylhydrazyl radical (DPPH) which forms a violet solution and reacts with antioxidants by losing color. Ten $\mu \mathrm{L}$ of each extract was mixed with $100 \mu \mathrm{M}$ DPPH in methanol in a final volume of $1 \mathrm{~mL}$. The changes were monitored over $20 \mathrm{~min}$. A control was prepared as described above without samples or standards. Methanol was used for the baseline correction. The changes in the absorbance of all the samples and standards were measured at $517 \mathrm{~nm}$. Radical scavenging activity was expressed as the inhibition percentage and was calculated using the following formula: percent of radical scavenging activity $=$ (control optical density-sample optical density/control optical density) $\times 100$. Ascorbic acid was chosen as a standard antioxidant and extract activity is expressed in $\mu \mathrm{mol}$ of ascorbic acid equivalents per gram fresh weight of leaf.

\section{Lignin content analysis}

Protein and other UV-absorbing materials removal protocols were essential to avoid the measurement of these constituents together with lignin at $280 \mathrm{~nm}$. Five hundred milligrams of the plant material of each sample (the same age stem of basils based on leaf number and threadlike stem of the dodders) were homogenized in $2 \mathrm{~mL}$ water using a pestle and mortar and then transferred into a screwcap centrifuge tube and centrifuged at $1000 \mathrm{~g}$ for $10 \mathrm{~min}$ and the supernatant was removed. The pellet was washed two times with ethanol, then the pellet was soaked and incubated at room 
temperature for $24 \mathrm{~h}$ in methanol: chloroform (1:2), the supernatant was removed and rinsed with acetone. The pellet was dried in an oven $\left(60{ }^{\circ} \mathrm{C}, 24 \mathrm{~h}\right)$ and cooled in a vacuum desiccator. The dry matter obtained was defined as the protein-free cell wall fraction (Hatfield et al. 1999).

Lignin content was determined according to a modified Iiyama and Wallis method (1990). Protein-free cell wall sample $(20 \mathrm{mg}$ ) was placed into a screwcap centrifuge tube containing $0.5 \mathrm{~mL}$ of $25 \%$ acetyl bromide ( $\mathrm{v} / \mathrm{v}$ in glacial acetic acid) and incubated at $70{ }^{\circ} \mathrm{C}$ for $30 \mathrm{~min}$. Samples also contained $100 \mu \mathrm{L}$ of perchloric acid to aid in the total dissolution of the wall material. After complete digestion, the sample was quickly cooled in an ice bath, and mixed with $0.9 \mathrm{~mL}$ of 2 $\mathrm{M} \mathrm{NaOH}$ and $6 \mathrm{~mL}$ of glacial acetic acid sufficient for complete solubilization of the lignin extract, and then samples were diluted to $25 \mathrm{~mL}$ with acetic acid. After centrifugation at $1000 \mathrm{~g}$ for $5 \mathrm{~min}$, the absorbance of the supernatant was measured at $280 \mathrm{~nm}$. Guaiacol was used as a standard and the results were expressed in milligrams of guaiacol equivalent per gram fresh weight of basil stem.

\section{Phenylalanine ammonia lyase (EC 4.3.1.5) enzyme assay}

Three hundred milligrams of plant material of each sample (the 5th basil leaf counted from the cotyledon and threadlike stem of $C$. campestris) was homogenized in an ice cold mortar using $50 \mathrm{mM}$ Tris- $\mathrm{HCl}$ buffer $(\mathrm{pH}=8.8)$ containing $10 \mathrm{mM}$ 2- $\beta$-mercaptoethanol, $1 \mathrm{mM}$ ethylenediaminetetraacetic acid (EDTA) and $2.5 \%$ polyvinylpyrrolidone (PVP). The mixture was centrifuged at $20000 \mathrm{~g}$ for $20 \mathrm{~min}$ and the clear supernatant was desalted in aliquots using an Amicon Ultra-15 Centrifugal Filter Units with Ultracel-50 membrane (Merck Millipore, Germany) and assayed for PAL activity. PAL activity was determined according to the method of Şirin et al. (2016). The enzyme reaction mixture contained $400 \mu \mathrm{L}$ of reaction buffer ( $100 \mathrm{mM}$ Tris- $\mathrm{HCl}, \mathrm{pH} 8.8)$ and 200 $\mu \mathrm{L}$ of substrate ( $40 \mathrm{mM}$ L-phenylalanine, $100 \mathrm{mM}$ Tris- $\mathrm{HCl}$, $\mathrm{pH} 8.8$ ) and a $200 \mu \mathrm{L}$ aliquot of the sample filtrate (or $200 \mu \mathrm{L}$ of deionised water used as a blank). The reaction was carried out at $37^{\circ} \mathrm{C}$ for $30 \mathrm{~min}$ and terminated by the addition of $50 \mu \mathrm{L}$ of $4 \mathrm{M} \mathrm{HCl}$, and the cinnamic acid concentration was measured spectrophotometrically by the absorbance at 290 $\mathrm{nm}$. One unit of PAL activity is equal to $1 \mu \mathrm{mol}$ of cinnamic acid produced per min. The enzyme activity was expressed in U per milligram protein. Protein content was determined according to the method of Bradford (1976) using bovine serum albumin as standard.

\section{Data analysis}

The experiments were performed by a factorial arrangement, based on complete randomized design. Obtained data were the average of the replications and two repetitions of each experiment, because there was no interaction. Results were determined using analysis of variance (ANOVA) via statistical analysis software (SAS, Version 9.4, SAS Institute Inc., Cary, NC, USA). The univariate procedure of SAS was used to test for normality of residuals. Each column value in figures represents mean \pm standard deviation (SD). Means were compared using Fisher's protected least significant differences (LSD) test. Differences at $\mathrm{P} \leq 0.05$ were considered to be significant.

\section{Results}

In the present study, we observed that the infestation percentage of $C$. campestris in basil that was not treated with carrageenan was $60.48 \%$, but in carrageenan-treated basil plants a significantly lower attachment of C. campestris, $33.93 \%$, was recorded. These findings showed that the infestation of basil plant treated with carrageenan by C. campestris decreased by about 26\% (Tab. 1), and therefore spraying with carrageenan significantly increased the resistance of basil plants to C. campestris invasion. C. campestris attachment occurred along the shoot of control plants (Fig. 1), but in basils which were sprayed with carrageenan, it was observed only at shoot apical part with newly formed organs (stem, leaves and petioles).

Tab. 1. Effect of foliar application of carrageenan $\left(1 \mathrm{~g} \mathrm{~L}^{-1}\right)$ and Cuscuta campestris invasion on the growth parameters of Ocimum basilicum (basil) and percentage of Cuscuta infestation. B0 - basil sprayed with water (control); B1 - basil sprayed with carrageenan; B0+D - basil parasitized by C. campestris; $\mathrm{B} 1+\mathrm{D}-$ basil sprayed with carrageenan and parasitized by C. campestris. Values are mean $\pm \mathrm{SD}$ of twenty replications. The different letters in the same column indicate significant difference at $\mathrm{P} \leq 0.05$.

\begin{tabular}{cccc}
\hline Treatments & Shoot length $(\mathrm{cm})$ & Leaf area $\left(\mathrm{cm}^{2}\right)$ & $\begin{array}{c}\text { Cuscuta } \\
\text { infestation (\%) }\end{array}$ \\
\hline $\mathrm{B}_{0}$ & $22.05^{\mathrm{b}} \pm 1.56$ & $5.91^{\mathrm{b}} \pm 0.43$ & - \\
$\mathrm{B}_{1}$ & $24.325^{\mathrm{a}} \pm 0.99$ & $8.43^{\mathrm{a}} \pm 0.95$ & - \\
$\mathrm{B}_{0}+\mathrm{D}$ & $13.625^{\mathrm{d}} \pm 0.54$ & $4.06^{\mathrm{c}} \pm 0.73$ & $60.48^{\mathrm{a}} \pm 2.69$ \\
$\mathrm{~B}_{1}+\mathrm{D}$ & $16.375^{\mathrm{c}} \pm 0.60$ & $6.09^{\mathrm{b}} \pm 0.71$ & $33.93^{\mathrm{b}} \pm 2.23$ \\
\hline
\end{tabular}
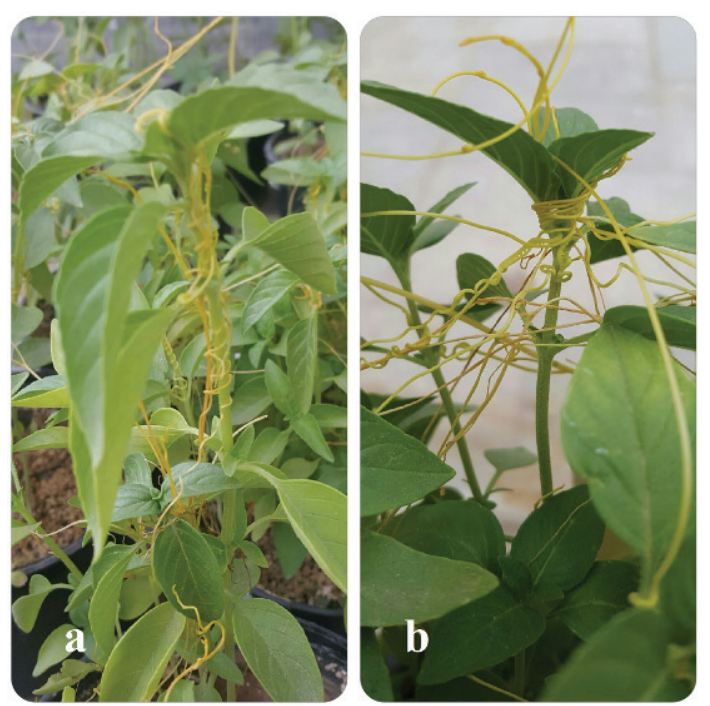

Fig. 1. Infestation of basil plants Ocimum basilicum by Cuscuta campestris: a) control and b) carrageenan treated basil plant. 
Infestation of $C$. campestris significantly decreased the shoot length and leaf area of basil, and the carrageenan treatment significantly increased the growth parameters in comparison with the carrageenan-untreated set of basil (Tab. 1). Therefore, it seems that the foliar application of carrageenan significantly alleviated the negative effect of the parasite $(C$. campestris) on the growth of infested host plants (Tab. 1).

The carrageenan treatment alone caused a significant increase of PAL activity and phenolic and antioxidant content of basil. Moreover, basil plants parasitized by C. campestris showed significantly higher PAL activity, phenolic, flavonoids and antioxidant content (Fig. 2).

The lignin content of the carrageenan treated-basil did not show significant changes compared to the control set but the carrageenan treatment significantly increased the lignin content of basil plants that were parasitized by C. campestris (Fig. 2).

In this study, we did not observe any significant change in phenolics, flavonoids, antioxidant, anthocyanin and lignin content of the C. campestris attached to the control group of basil plants and C. campestris from basil hosts treated with carrageenan (Fig. 2).

\section{Discussion}

Besides microbial pathogens and herbivorous arthropods, plants can also be parasitized by other plants. Cuscuta species is recognized to cause serious economic losses in crop plants. In this study, infestation by C. campestris significantly decreased the shoot length and leaf area of basil. Generally, with regards to the infected plant species, Cuscuta invasion has been reported severely to affect the growth and reproduction of its host (Lanini and Kogan 2005). Some researchers have shown that parasitic flowering plants of the genus Cuscuta, most especially C. campestris Yunck., C. australis $\mathrm{R}$. Br. and C. chinensis Lam., can significantly reduce their host's growth (Zan et al. 2003, Lanini and Kogan 2005). Also Farah and Al-Abdulsalam (2004) showed that
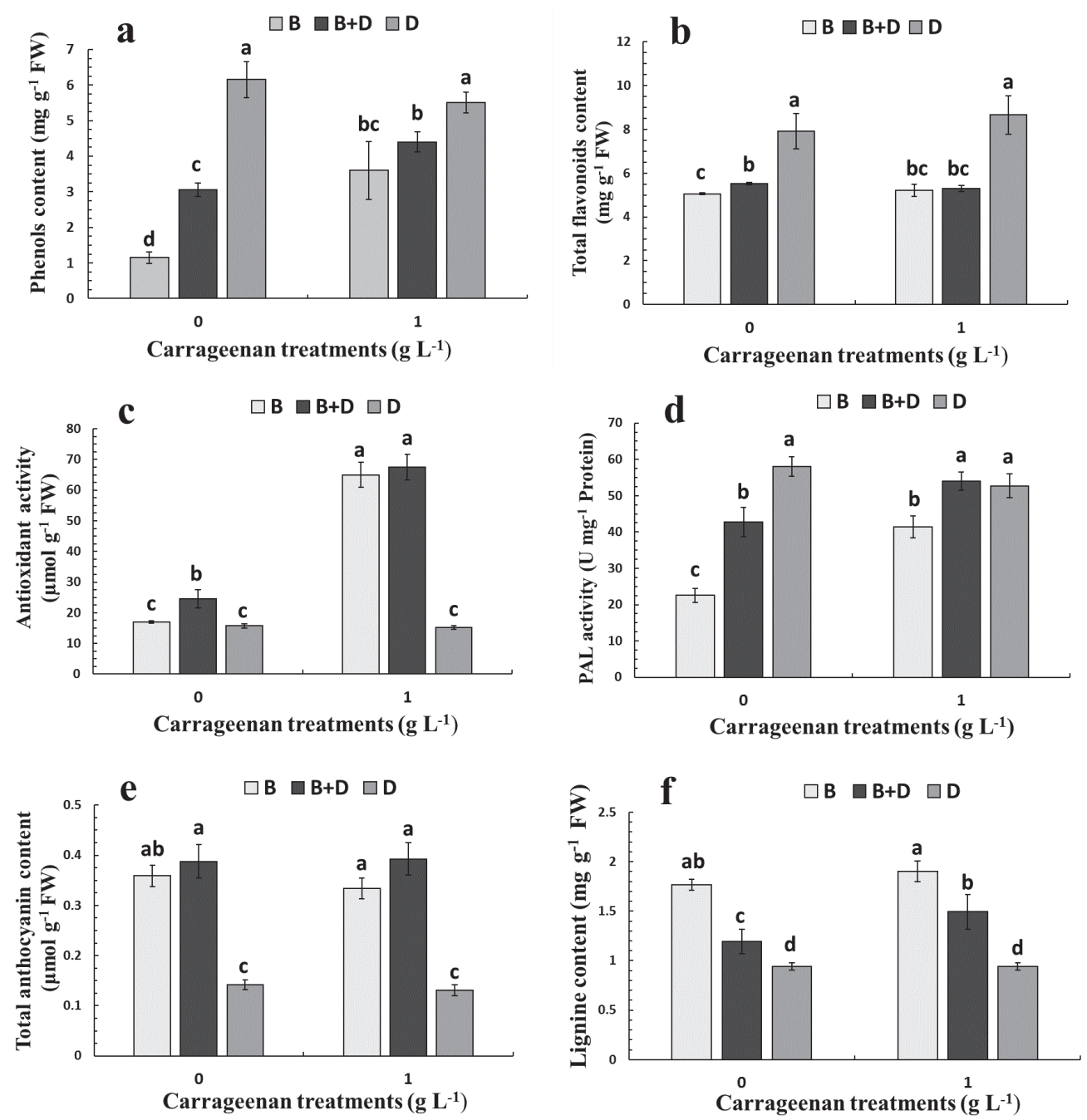

Fig. 2. Effect of foliar application of carrageenan and Cuscuta campestris invasion on the biochemical parameters of basil leaves and Cuscuta stems: a) phenol content, b) total flavonoid content c) antioxidant content, d) phenylalanine ammonia-lyase activity (PAL), e) total anthocyanin content, $\mathrm{f})$ lignin content. Values represent mean \pm standard deviation $(\mathrm{n}=3)$. Different letters above bars indicate significant difference at $\mathrm{P} \leq 0.05$. $\mathrm{B}$ - basil; $\mathrm{B}+\mathrm{D}$ - basil parasitized by C. campestris; $\mathrm{D}-$ C. campestris 
C. campestris caused variable reductions in the vegetative (plant height, dry weights of shoot and root systems, number of leaves per plant) and reproductive (number of pods per plant and number of flowers per plant) traits of numerous legume crops. Although Cuscuta contains a few chloroplasts and slight chlorophylls, and thus possesses an extremely low photosynthetic activity, it is believed to be absolutely dependent on its host for nutrient sources (Birschwilks et al. 2006, Furuhashi et al. 2014) and will severely inhibit the growth of the host by removing its resources for photosynthesis, growth and leaf production. In addition, Cuscuta spp. forms a dense, thick mat over the host, which decreases the sun's radiation and consequently photosynthesis and growth (Dawson et al. 1994).

The specific pathways involved in defense against parasitic plants are unknown. In this research we showed that $C$. campestris induced PAL activity and increased phenolic and flavonoid content in the basil plants. It has been well documented that responses of host plants to attack by C. reflexa include a hypersensitive-like response and phytoalexin production (Borsics and Lados 2002). Best studied among host plant defenses against Cuscuta sp. is the resistance responses of tomato plants to C. reflexa, in which elongation of hypodermal host cells, accumulation of phenolics and peroxidases at binding site create a mechanical barrier that can block haustorial formation (Sahm et al. 1995). Our results confirmed that C. campestris infestation increased the flavonoid levels in host plants.

The application of herbicides to manage weed populations is very common but is not nature friendly and is not suitable for all situations. Therefore, other ways of control, such as biological control, more friendly to the environment and humans, are necessary (Rosskopf et al. 1999). Carrageenans are recognized to elicit defense responses in plants and animals against various plant pathogens and mammalian viruses (Khan et al. 2009). The effect of carrageenans on plant resistance to weeds is not known, and in this research we investigated the effects of $\mathrm{k}$-carrageenan on sweet basil resistance to Cuscuta campestris infestation. In this study, the application of external carrageenan enhanced shoot length and leaf area of basil and alleviated the negative effect of the parasite on the growth of infested plants. It is known that $\kappa, \lambda$ and $\mathrm{t}$-carrageenans at a concentration of $1 \mathrm{mg} \mathrm{mL}^{-1}$ increased shoot height and leaf biomass in tobacco plants by increasing the net photosynthesis, rubisco activity, the glutamate dehydrogenase activity involved in nitrogen assimilation, basal metabolism, and cell proliferation (Castro et al. 2012, Gonzàlez et al. 2013a). Also, there is a report showing that seaweed extracts improved nutrient uptake by roots, thereby causing enhanced plant growth (Mancuso et al. 2006). In this research, the anti-infestation activities of carrageenan were observed. Infestation by C. campestris of basil plants treated with carrageenan decreased by about $26 \%$. Carrageenantreated basil plants attracted fewer C. campestris as compared to the control. It has been reported that the chemical reactivity of carrageenans is mostly due to their half-ester sulfate groups that are extremely anionic (Necas and Bartosikova 2013). These negatively charged compounds perform their inhibitory effect by interacting with the positive charges on the cell wall surface of parasite plants and thereby prevent the prehaustorium attachment and entrance into the host cells. In addition, the negative charge and antioxidant properties (Yuan et al. 2006) of carrageenan probably cause inhibition of hydrolysis enzymes inside the cell wall of C. campestris, causing the inhibition of prehaustorium penetration in the host cell wall. Moreover, it seems likely that $\kappa$-carrageenan induces several biochemical pathways in the development of plant resistance. In this work, C. campestris attachment occurred along the stem of control group of basil plants, but in basil with foliar spray of carrageenan few infections occurred in shoot apical parts not affected by carrageenan, because these organs were formed after carrageenan treatment.

A recent study has shown that seaweed extracts can be used as an important source of plant defense elicitors (Khan et al. 2009). Besides influencing the physiology and metabolism of plants, it has been reported that $\mathrm{K}$-carrageenan is very effective and induces maximum browning and high level of secondary metabolites (pathogen resistance compounds) in various crop plants like chickpea, carrots and potatoes (Bi et al. 2008). In addition $\mathrm{K}$-carrageenan is an effective substance for induction of defensive genes in tobacco leaves (Mercier et al. 2001). We demonstrated that plant defense response was induced by $\mathrm{k}$-carrageenan. Carrageenan treatment caused a significant increase in the PAL activity and phenolic compound of basil, but flavonoid and anthocyanin content did not show considerable changes. Induction of PAL activity, the first and key enzyme of the phenylpropanoid pathway (Vera et al. 2012) induces the accumulation of some phenyl propanoid compounds (PPCs) in tobacco plants. It has been reported that $\kappa$-, $\lambda$ - and $\mathrm{l}$-carrageenans increase protection against fungal, viral, and bacterial infection in tobacco plants, which was due, at least in part, to the accumulation of PPCs (Vera et al. 2011). Also, it has been reported that oligo-carrageenans increased growth and activated defensive mechanisms against pathogens by enhancing the amount of some PPCs in eucalyptus trees (Gonzàlez et al. 2013a, b). We observed that in basil, $\mathrm{k}$-carrageenans elicited PAL enzyme activities, with the consequence of a higher phenolic content. The phenolics are implicated in plant defense through scavenging reactive oxygen species (Cho and Lee 2015). Phenolic compounds are also involved in the defense response through reinforcement of the cell wall by biopolymer deposition near parasite infestation sites. In accordance with this explanation, the present study showed carrageenan treatment increased the lignin content of a basil plant parasitized by C. campestris, which is a desirable trait that may be associated with resistance of basil against $C$. campestris invasion. Deposition of lignin has been hypothesized to interfere with the enzymatic hydrolysis and mechanical penetration of host plant tissue by Cuscuta and may also weaken the movement of water and diffusible molecules between host and Cuscuta and help to starve the parasite (Lattanzio et al. 
2006). As pointed out, the ability of $C$. campestris haustorium to penetrate from a looser site of the basil stem was the cause of the lower lignin content in the parasitized basil plant than in the control. This research demonstrates the ability of carrageenan to modulate the resistance of basil to C. campestris. The mechanism of this suppression is not clearly known, but we believe that the activation of natural plant resistance mechanisms and the ability of carrageenan to stimulate the synthesis of compounds (secondary metabolites) with antiinfestation activities will be the cause. Importantly, this study is the first indication that carrageenan treatment can directly suppress infestation of the basil plant by C. campestris.

In this study, antioxidant content increased remarkably in basil plants with C. campestris infestation and carrageenan treatment. The antioxidative effect is mainly due to phenolic components, which can act as reducing agents, hydrogen donors, and singlet oxygen quenchers. They may also have a metal chelating potential (Niccholson 1992). Basil

\section{References}

Aly, R., 2013: Trafficking of molecules between parasitic plants and their hosts. Weed Research 53, 231-241.

Behbahani, M., 2014: Evaluation of in vitro anticancer activity of Ocimum basilicum, Alhagi maurorum, Calendula officinalis and their parasite Cuscuta campestris. PLoS ONE 9, 1-13.

Bi, F., Iqbal, S., Arman, M., Ali, A., Hassan, M. U., 2011: Carrageenan as an elicitor of induced secondary metabolites and its effect on various growth characters of chickpea and maize plants. Journal of Saudi Chemical Society 15, 269-273.

Bi, F., Iqbal, S., Ali, A., Arman, M., Hassan, M. U., 2008: Induction of secondary metabolites in chickpea, carrot and potato tissues in response to elicitor of Hypnea musciformis. Indian Journal of Plant Physiology 13, 101-106.

Birschwilks, M., Haupt, S., Hofius, D., Neumann, S., 2006: Transfer of phloem-mobile substances from the host plants to the holoparasite Cuscuta sp. Journal of Experimental Botany 57, 911-921.

Borsics, T., Lados, M., 2002: Dodder infection induces the expression of a pathogenesis-related gene of the family PR-10 in alfalfa. Journal of Experimental Botany 53, 1831-1832.

Bradford, M. M., 1976: A rapid and sensitive method for quantitation of microgram quantities of protein utilizing the principle of protein-dye binding. Analytical Biochemistry 72, 248-254.

Castro, J., Vera, J., Gonzàlez, A., Moenne, A., 2012: Oligo-carrageenans stimulate growth by enhancing photosynthesis, basal metaboism, and cell cycle in tobacco plants var. Burley. Journal of Plant Growth Regulation 31, 173-185.

Chang, C. C., Yang, M. H., Wen, H. M., Chern, J. C., 2002: Estimation of total flavonoid content in propolis by two complementary colorimetric methods. Journal of Food and Drug Analysis 10, 178-182.

Chiang, L. C., Cheng, P. W., Chiang, W., Lin, C. C., 2005: Antiviral activity of extracts and selected pure constituents of Ocimum basilicum. Clinical and Experimental Pharmacology and Physiology 32, 811-816.

Cho, M. H., Lee, S. W., 2015: Phenolic phytoalexins in rice: biological functions and biosynthesis. International Journal of Molecular Science 16, 29120-29133.

Craigie, J. S., 2011: Seaweed extract stimuli in plant science and agriculture. Journal of Applied Phycology 233, 371-393. plants possess valuable antioxidant properties that may be associated with lower incidence and lower mortality rates of cancer in several human populations (Gülçin et al. 2007). Our findings support the idea that treatment of basil plants with carrageenan stimulated the activation of the phenylpropanoid pathway, which may lead to the accumulation of phenolic compounds. Thus, carrageenan foliar treatment of host plants may be directly and indirectly involved in the resistance mechanism to parasitic plants. Because carrageenans are non-toxic biodegradable, non-polluting and non-hazardous to humans, animals and birds, they can be recommended as natural biostimulators for the protection of plants against parasitic C. campestris plants.

\section{Acknowledgments}

The authors also appreciate Dr. Ghotbzadeh and Dr. Mirtajadini for their help in the statistical analysis and identification of plant species, respectively.

Creelman, R. A., Mullet, J. E., 1997: Oligosaccharins, brassinolides, and jasmonates: nontraditional regulators of plant growth, development, and gene expression. Plant Cell 9, 1211-1223.

Dawson, J. H., Musselman, L. J., Wolswinkel, P., 1994: Biology and control of Cuscuta. Weed Science 6, 265-317.

Farah, A. F., Al-Abdulsalam, M. A., 2004: Effect of feld dodder on some legume crops. Scientific Journal of King Faisal University $5,103-113$.

Fathoulla, C. N., Duhoky, M. M. S., 2008: Biological and anatomical study of different Cuscuta species. Journal of Dohuk University 111, 22-39.

Furuhashi, T., Fragner, L., Furuhashi, K., Valledor, L., Suna, X., 2012: Metabolite changes with induction of Cuscuta haustorium and translocation from host plants. Journal of Plant Interactions 7, 84-93.

Furuhashi, T., Kojima, M., Sakakibara, H., Fukushima, A., Yokota, H. M., 2014: Morphological and plant hormonal changes during parasitization by Cuscuta japonica on Momordica charantia. Journal of Plant Interactions 9, 220-232.

Gao, X., Ohlander, M., Jeppson, N., Bjork, L., Trajkovski, V., 2000: Changes in antioxidamt effects and their relationship to phytonutrients in fruits of sea buckthorn (Hippophae rhamnoides L.) during maturation. Journal of Agricultural and Food Chemistry 48, $1485-1490$.

Girennavar, B., Jayaprakasha, G. K., Jadegoud, Y., Nagana Gowda, G. A., Patil, B. S., 2007: Radical scavenging and cytochrome P450 3A4 inhibitory activity of bergaptol and geranylcoumarin from grapefruit. Bioorganic and Medicinal Chemistry 15, 3684-3691.

Gonzàlez, A., Castro, J., Vera, J., 2013a: Seaweed oligosaccharides stimulate plant growth by enhancing carbon and nitrogen assimilation, basal metabolism, and cell divition. Journal of Plant Growth Regulation 32, 443-448.

Gonzàlez, A., Rodrigo, A. C., Moenne, A., 2013b: Oligo-carrageenans enhance growth and contents of cellulose, essential oils and polyphenolic compounds in Eucalyptus globulus trees. Molecules 18, 8740-8751.

Gülçin, I., Elmastaş, M., Aboul-Enein, H. Y., 2007: Determination of antioxidant and radical scavenging activity of basil Ocimum basilicum L. (family Lamiaceae) assayed by different methodologies. Phytotherapy Research 21, 354-361. 
Halim, V. A., Hunger, A., Macioszck, V., 2004: The oligopeptide elicitor Pep-13 induces salicylic acid-dependent and -independent defense reactions in potato. Physiological And Molecular Plant Pathology 64, 311-318.

Hanlon, J. E., 2015: Soil pH and electrical conductivity: A county extension soil laboratory manual. IFAS Extension Service, University of Florida, 1-10.

Hashmi, N. M., Khan, A., Masroor, M., Idrees, M., Khan, Z. H., Ali, A., Varshney, L., 2012: Depolymerized carrageenan ameliorates growth, physiological attributes, essential oil yield and active constituents of Foeniculum vulgare Mill. Carbohydrate Polymers 901, 407-412.

Hatfield, R. D., Grabber, J., Ralph, J., Brei, K., 1999: Using the acetyl bromide assay to determine lignin concentrations in herbaceous plants: some cautionary notes. Journal of Agricultural and Food Chemistry 47, 628-632.

Hong, L., Shen, H., Chen, H., Hu Li, L., Xinlan, X., 2011: The morphology and anatomy of the heustoria of the holoparasitic angiosperm Cuscuta campestris. Pakistan Journal of Botany 43, 1853-1859.

Iiyama, K., Wallis, A. F. A., 1990: Determination of lignin in herbaceous plants by an improved acetyl bromide antioxidant activity and flavonoid content in blackberries (Rubus sp.) and promotes anti proliferation and promotes antiproliferation of human cancer cells. Food Chemistry 107, 1261-1269.

Jatinder, S. S., Khan, W., Ji, X., 2011: Carrageenans, sulphated polysaccharides of red seaweeds, differentially affect Arabidopsis thaliana resistance to Trichoplusiani (cabbage looper). PLoS ONE 6,1-11.

Kapooria, R., 2007: An overview of biological control of fruit and vegetable diseases. In: Pandey, A., Mukerji, K.G. (eds.), Biological control of plant diseases, 191-211. The Haworth Press, Inc. New York.

Khan, W., Rayirath, U. P., Subramanian, S., Mundaya, N. J., Rayorath, P., 2009: Seaweed extracts as biostimulants of plant growth and development. Journal of Plant Growth Regulation 28, 386-399.

Kushan, U.T., Duncan, D. C., 2006: The anatomy of Santalum album (sandawood) haustoria. Canadian Journal of Botany. 84, 1608-1616.

La Caméra, S. G., 2004: Metabolic reprogramming in plant innate immunity: the contributions of phenyl propanoid and oxylipin pathways. Immunological Reviews 198, 267-284.

Lanini, W., Kogan, M., 2005: Biology and management of Cuscuta in crops. Ciencia e Investigación Agraria 32, 165-179.

Lattanzio, V., Lattanzio, V. M. T., Cardinali, A., 2006: Role of phenolics in the resistance mechanisms of plants against fungal pathogens and insects. Phytochemistry: Advances in Research 661, 23-67.

Liao, G. I., Chen, M. Y., Kuob, C. S., 2005: Distribution and host range of Cuscuta in taiwan, kinmen and mastu, with special reference to host preference of $C$. japonica. Journal of Biology $40,17-24$.

Mancuso, S., Azzarello, E., Mugnai, S., Brianf, X., 2006: Marine bioactive substances (IPA extract) improve foliar ion uptake and water tolerance in potted Vitis vinifera plants. Advances in Horticultural Science 20, 156-161.

Mercier, L., Lafitte, C., Borderies, G., Briand, X., Tugaye, M. T. E., Fournier, J., 2001: The algal polysaccharide carrageenans can act as an elicitor of plant defence. New Phytologist 14, 43-51.

Naeem, M., Aftab, T., Ansari, A. A., Idrees, M., Ali, A., Masroor Khan, M., Uddin, M., Varshney, L., 2012: Depolymerised carrageenan enhances physiological activities and menthol production in Mentha arvensis L. Carbohydrate Polymers 87, 1211-1218.
Necas, J., Bartosikova, L., 2013: Carrageenan: a review. Veterinarni Medicina 5, 187-205.

Niccholson, R. L., 1992: Phenolic compounds and their role disease resistance. Annual Review of Phytopathology 30, 369389.

Potin, P., Bouarab, K., Kupper, F., Kloareg, B., 1999: Oligosaccharide recognition signals and defence reactions in marine plant-microbe interactions. Current Opinion in Microbiology 2, 276-283.

Ramasubramania, R. R., 2012: Medicinally potential plants of Labiatae (Laminaceae) family: An overview. Research Journal of Medicinal Plant 6, 203-213.

Rao, R. S., Sarada, R., Ravishankar, G. A., 1996: Phycocyanin, a new elicitor for capsaicin and anthocyanin accumulation in plant cell cultures. Applied Microbiology and Biotechnology $46,619-621$

Rosskopf, E. N., Charudattan, R., Kadir, J. B., 1999: Use of plant pathogens in weed control. In: Fisher, T. W., Bellows, T. S., Caltagirone, L. E., Dahlsten, D. L., Huaker, C., Gordh, G. (eds.), Handbook of biological control, 891-918. Academic Press, San Diego.

Sahm, A., Pfanz, H., Grunsfelder, M., Czygan, F. C., Proksch, P., 1995: Anatomy and phenylpropanoid metabolism in the incompatible interaction of Lycopersicon esculentum and Cuscuta. Botanica Acta 108, 358-364

Shen, H., Hong, L., Ye, W. H., Cao, H. L., Wang, Z. M., 2007: The influence of the holoparasitic plant Cuscuta campestris on the growth and photosynthesis of its host Mikania micrantha. Journal of Experimental Botany 58, 2929-2937.

Shukla, P. S., Borza, T., Critchley, A. T., Prithiviraj, B., 2016: Carrageenans from red seaweeds as promoters of growth and elicitors of defense response in plants. Frontiers in Marine Science 3:81 doi: 10.3389/fmars.2016.00081.

Şirin, S., Aydas, S. B., Aslim, B., 2016: Biochemical evaluation of phenylalanine ammonia lyase from endemic plant Cyathobasis fruticulosa (Bunge) Aellen. for the dietary treatment of phenylketonuria. Food Technology and Biotechnology 54, 296-303.

Tewari, D., Sah, A. N., Pandey, H. K., Meena, H. S., 2012: A review on phytoconstituents of Ocimum (Tulsi). International Journal of Ayurvedic Medicine 3, 1-9.

Vera, J., Castro, J., Gonzàlez, A., Moenne, A., 2011: Seaweed polysaccharides and derived oligosaccharides stimulate defense responses and protection against pathogens in plants. Marine Drugs 9, 2514-2525.

Vera, J. C., 2012: Oligo-carrageenans induce a long-term and broad-range protection against pathogens in tobacco plants var. xanthi. Physiological and Molecular Plant Pathology 79, 31-39.

Wagner, G., 1979: Content and vacuole/extra vacuole distribution of neutral sugars free amino acids and anthocyanins in protoplast. Plant Physiology 64, 88-93.

Yuan, H. M., Song, J. M., Zhang, W. W., Li, X. G., Li, N., Gao, X. L., 2006: Antioxidant activity and cytoprotective effect of $\kappa$-carrageenan oligosaccharides and their different derivatives. Bioorganic and Medicinal Chemistry Letters 16, 1329-1330.

Zan, Q. J., Wang, B. S., Wang, Y. J., Zhang, J. L., Liao, W. B., Li, M. G., 2003: The harm caused by Mikania micrantha and its control by Cuscuta campestris. Journal of Plant Ecology 27, 822-828.

Zhang, X., Ervin, E. H., Schmidt, E. R., 2003: Plant growth regulators can enhance the recovery of Kentucky bluegrass sod from heat injury. Crop Science 43, 952-956. 